\title{
A New Model for Respiratory Care in General Practice: The CATS model for respiratory car
}

\section{Woodforde Christophe}

Peelhouse Lane Surgery, Widnes, Cheshir

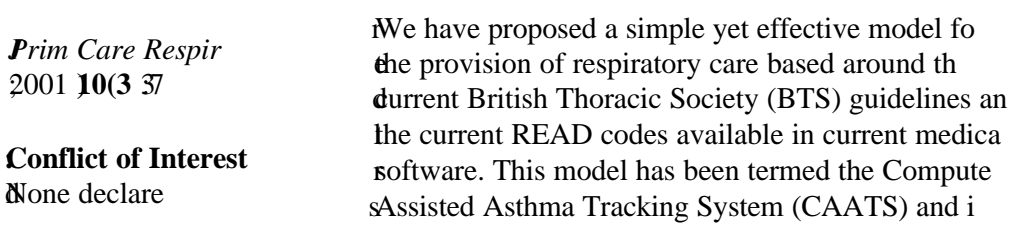

\begin{abstract}
sasily implemented in most computer systems. Thi model permits easy monitoring and subsequent audi bf the provision of respiratory care in genera practice. In our practice all respiratory patients ar reviewed in the generic Chest Clinic. The mode comprises of five simple steps of care
\end{abstract}

\section{1) Step 1 - Recognitio}

- written invitations for patients to attend the Chest Clinic

- opportunistic health screening

- monitoring of repeat inhaler prescribing

- spirometer screening of patient with smoking histories

- monitoring of hospital discharge summaries

\section{3) Step 3 - Revie}

- systematic review of sympto control, peak-flow/spirometry, erigger factor avoidanc

- adjustment of inhaled/oral sherapie

- the setting of a further date for reassessmen

\section{6) Rescue Uni}

This is the 'blue light' which is designe D standardise emergency asthma/COP management. It comprises:

- A fully operational nebuliser on stand-by accompanied by laminated action cards on emergency asthma/COPD management

- Dedicated referral letters and stationery

- Appointment cards for subsequent revie

\section{Reference Unit}

This is a database of information held in ring binder file for all practice staff to refe to when required. It includes copies of

- Current BTS guidelines (Asthma/COPD

- Local respiratory guideline

- The practice formular

\section{8) Recall Unit}

This is a system to 'chase' patient pefaulting their initial, or follow-u appointments

tTheir progress is tracked through curren READ code

\section{2) Step 2 - Registratio}

- Attends for formal assessment by practice nurse/GP

- Defaults assessment

- Standardised medical template' collecting all the relevant asthma/COPD) data is completed;

- Therapy is evaluated; Vaccinations are offered;

- ;Written Action Management Plan (AMP) is devised in conjunction with the patient

- Notes and computer files we labelled:(READ Codes Asthma stage 1 (8794 Asthma stage $2 \quad(8795$ Asthma stage 4 (8797 Asthma stage 5 (8798 No longer asthmatic stage 0 (8793 Mild COPD (H36) Moderate COPD (H37

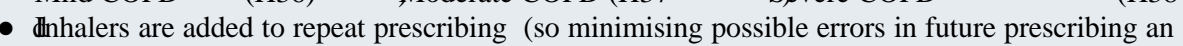
permitting subsequent audit

- A review date is agreed, documented and logged in the computer

\section{Step 4 - Reassessment}

- systematic review of sympto control, peak-flow/spirometry, erigger factor avoidanc

- adjustment of inhaled/oral sherapie

- the setting of a further date for further reassessmen

\section{5) Step 5 - Referra}

- Patients may require referral to other agencies at any stage of the process e.g. GP, Hospital OPD, Rapid Response Respiratory team (RRRT), Hospital (as an emergency), Rescue unit or Pulmonary rehabilitation

Criteria for referral are those proposed by the BTS
The above system is designed to be easil implemented in most modern practices an oan be adapted to run with practices based o domputer only' record systems or 'combine computer/ paper' record systems

By the use of established READ codes practices can implement effective respirator data registers with the aid of establishe medical computer software. Respirator patients can be easily identified and targete ho that clinical care and standards bot improve in practice

Qver the two years that we have been usin the system, we have noticed a dramatic fall $\mathrm{i}$ the number of acute exacerbations. We hav established an effective and dynami respiratory register, reduced the ove prescribing of $\beta \mathrm{k} 2$-agonists and have bee

\section{READ Codes Use}

,90J4 asthma monitor 1st letter, $68 \mathrm{c} 3$ asthma screening, $90 \mathrm{~J} 7$ asthma monitor verbal invite $68 \mathrm{M}$ spirometric screening, - emergency admission- asthma, 6631- initial respirator Assessment, 90J3 asthma monitor offer default, 6632 follow-up respiratory assessment, 90J Asthma monitoring check done, H33z1 Asthma NOS, H33z1 asthma attack, 90JS asthm monitor 2nd letter, $90 \mathrm{~J} 6$ asthma monitor 3rd letter, 90J7 asthma monitor verbal invite, $90 \mathrm{~J} 8$ asthma monitor phone invite, $90 \mathrm{~J} 2$ refuses asthma monitoring. 